\title{
Martuccelli, Danilo. Lima y sus arenas. Poderes sociales y jerarquías culturales. Lima: Cauces, 2015, 326 pp.
}

En el libro Lima y sus arenas, D. Martuccelli, su autor, plantea una serie de formulaciones conceptuales a través de las cuales busca articular una nueva narrativa desde las ciencias sociales que sea comprehensiva de las intensas transformaciones que se vienen dando en Lima y en el Perú contemporáneo en las últimas décadas. Mi lectura del libro lleva el sesgo de mis propias investigaciones e interpretaciones sobre el Perú de hoy, que se articulan en torno a lo que denomino el neoliberalismo como régimen cultural (Cánepa 2012; 2013). A la luz de estas reflexiones, identifico algunos aspectos problemáticos de la propuesta de Martuccelli que a mi parecer constituyen las debilidades conceptuales más resaltantes de su proyecto interpretativo.

Martuccelli empieza por constatar una serie de transformaciones sociales y culturales ocurridas en la ciudad de Lima en las últimas décadas y propone que su estudio ofrece la clave para entender finalmente a Lima en su especificidad. La relevancia de incidir en esta especificidad consistiría en que ofrece la posibilidad de romper con una larga tradición, ampliamente instalada en nuestro sentido común, que confunde Lima con el Perú. Por otro lado, el argumento general del libro acerca de la emergencia de un fenómeno específicamente limeño se sustenta en la constatación que el autor hace de dos procesos en curso. El primero se explicaría en términos de lo que este concibe como el tránsito del imaginario del mestizaje al imaginario de la fusión. Un segundo proceso en curso, corresponde al surgimiento, aunque aún incipiente, de una «cultura de las reglas» que sería resultado de lo que el autor denomina el proyecto reglamentador, el cual no estaría enmarcado en un proyecto institucional, sino que surgiría de la intersección entre los esfuerzos del propio Estado por lograr un desempeño más eficiente y las demandas de la población por justicia y por el cumplimiento de las reglas. Ambos procesos a su vez habrían dado lugar, por un lado, a un individualismo idiosincrático y popular, que Martuccelli denomina «individualismo metonímico» y que encuentra expresión en un «individuo que se percibe como un individuo hiper actor», y por el otro, a una nueva sociabilidad, puesta en práctica por este nuevo sujeto. En esta nueva sociabilidad, el individuo híper actor, a diferencia de los limeños de origen migrantes de la década de 1980, estaría en la capacidad de responder a las clasificaciones sociales, raciales y culturales de las que históricamente ha sido un objeto, instituyendo así nuevas formas de relacionamiento 
social y definición de sí mismo. Finalmente, para Martuccelli este nuevo sujeto no sería producto de un proyecto político o cultural de constitución de sujetos ciudadanos, sino resultado de las luchas que este lleva a cabo cotidianamente en la ciudad.

Según el planteamiento de Martuccelli, el tránsito de un imaginario del mestizaje a un imaginario de la fusión implica el paso de un orden definido por ataduras biológicas, así como de la tradición, cuyo sujeto tiene poco margen de acción, a uno nuevo en el cual este logra liberarse para afirmarse en nuevas subjetividades a través de la creatividad y la innovación. El autor entiende el mestizaje principalmente en términos biológicos y de forma esencialista. Este enfoque contrasta con una amplia bibliografía crítica sobre el mestizaje en el Perú y en América Latina, producida en las últimas casi tres décadas, y que se encuentra totalmente ausente en el libro. En este cuerpo bibliográfico, el mestizaje es más bien definido como una arena de argumentación (De la Cadena, 2004), en la cual las características fenotípicas y los repertorios culturales son intervenidos discursiva y performativamente - por actores particulares, en contextos cultural e históricamente específicos - con el fin de desarrollar argumentos identitarios de forma relacional y estratégica, ya sea para afirmarse en un lugar clasificatorio o para situarse en uno distinto. En el Perú, los trabajos sobre mestizaje han explorado ampliamente las formas en que, en tales arenas de disputa y negociación identitaria, las categorías de clase, raza, etnicidad y género se resignifican, a veces, por ejemplo, racializando la categoría de género y otras moralizando la categoría racial.

Desde la perspectiva teórica implicada en esta amplia bibliografía, completamente ausente en la discusión que plantea Martuccelli, se puede afirmar entonces que allí donde se lleva a cabo el trabajo de clasificación y definición identitaria estarán siempre implicados actores que, desde lugares estructurales diferenciados y con agendas distintas, ensayan su fuerza performativa. Además, implica entender que las categorías clasificatorias no constituyen realidades estancas claramente delimitadas, sino que son redefinidas y resignificadas de maneras complejas y, en ocasiones, paradójicas. En ese sentido, encuentro problemático negar agencia y capacidad de maniobra a los sujetos inmersos en el imaginario del mestizaje, para luego argumentar que lo particular del imaginario de la fusión sería el surgimiento de un individuo con gran capacidad de creación e innovación cultural capaz de redefinir el orden de clasificación social y su lugar en él. Identifico aquí una segunda debilidad en la discusión de Martuccelli, proponiendo más bien que lo que resulta particular al nuevo contexto en el que nos encontramos no es el 
surgimiento de un sujeto actor, sino más bien el de uno que debe responder al mandato de ser actor, de estar siempre en escena, y en búsqueda de un desempeño eficiente. Un homo performance implicado en una cultura del emprendimiento que da sentido a, y gestiona su vida, en términos de eficiencia y eficacia, así como de éxito (Cánepa 2012, 2013). Es precisamente esta dimensión normativa la que Martuccelli pasa por alto cuando se refiere al individuo hiper actor como el sujeto del imaginario de la fusión.

Mientras que el mestizaje es concebido en términos biológicos, Martuccelli atribuye a la fusión las nociones de hibridación, mezcla, o libertad creativa, planteando así una suerte de dicotomía entre mestizaje / fusión y biología / cultura. Pasando por alto una importante producción teórica y académica, Martuccelli desatiende el hecho que la noción de fusión necesita ser discutida en el marco de dinámicas de producción cultural que operan dentro de un régimen económico en el cual la cultura se ha constituido - en sus usos y definiciones- como recurso (Yúdice, 2002), y se gestiona según principios corporativos (Comaroff y Comaroff, 2009). La noción de fusión nos sitúa entonces en el ámbito del mercado, y requiere pensar en repertorios que adquieren valor como mercancías.

En ese sentido, discrepo con el planteamiento de Martuccelli cuando discute la música chicha como manifestación emblemática del imaginario de la fusión, para argumentar que esta daría lugar a una suerte de explosión creativa de la cual habría emergido una cultura chicha que habría permeado el conjunto de la sociedad limeña para dar lugar a una nueva sociabilidad. El problema central es que Martuccelli no distingue entre el fenómeno de la música chicha que surge en la década de 1980 y los fenómenos actuales, como el de la gastronomía o el diseño. Si bien la música chicha es el resultado de la mezcla y de la fusión de géneros musicales distintos y es imposible negar su importancia como una industria cultural, ya que entre otras cosas ha convertido a sus cultores en un público consumidor, esta implicó un proceso distinto, en un contexto distinto del de la gastronomía. Mientras que la chicha como género musical y luego como cultura se fue constituyendo en un campo de argumentación cultural en el cual lo que está en juego es la disputa sobre los términos de la propia definición de lo chicha. Lo que se observa con respecto a la gastronomía es más bien un proceso de apropiación cultural y de estilización o refinamiento, donde el producto de fusión está diseñado principalmente para conquistar nuevos públicos, más precisamente está pensada «para el mundo». Lo que está en juego en el desarrollo de repertorios gastronómicos no es realmente la adscripción identitaria, ni la definición de sus contenidos, sino el control sobre esta en tanto recurso económico. 
En Lima y sus arenas hay un tono celebratorio con respecto a las posibilidades que la fusión ofrecería en contraste al mestizaje. Y, encuentro en muchos pasajes del libro una afinidad con los discursos y narrativas provenientes de los estudios de marketing, como los de Rolando Arellano, y los de marca Perú, que abogan por una suerte de régimen post racial y post étnico, que han ido adquiriendo una importante presencia y legitimidad en el debate público. Identifico como una tercera debilidad del análisis de Martuccelli la falta de una perspectiva crítica atribuible precisamente a la ausencia de una discusión sobre las complejas dinámicas entre cultura y mercado, así como sobre la formulación de identidades en términos corporativos, que viene siendo central para entender procesos de formación ciudadana, y de identidades étnicas y nacionales en el marco de una gubernamentalidad neoliberal.

En esta misma línea de reflexión considero discutible el argumento de Martuccelli según el cual el surgimiento del individuo híper actor sería resultado, por un lado, de una reacción a la experiencia ampliamente extendida de abandono y desconfianza del Estado, y por el otro de una relectura de la idea ampliamente difundida desde la década de 1980 y desde distintas canteras ideológicas, según la cual el peruano - en particular el migrante provinciano- es un emprendedor nato. El autor continúa enfáticamente afirmando que este híper actor no es producto de un proyecto institucional, sino que surge de los avatares y luchas cotidianas, pero que habría, sin embargo, logrado instalarse en la vida de la ciudad otorgándole precisamente su carácter particular. Es esta espontaneidad y origen estrictamente popular que Martuccelli atribuye al surgimiento del nuevo sujeto limeño con la que discrepo.

Para ganar en fuerza interpretativa los conceptos del imaginario de la fusión y del individuo hiper actor requerirían una indagación en torno a las prácticas de consumo. De especial interés sería una discusión acerca de la amplia acogida que han recibido seminarios, convenciones, talleres y cursos de coaching y liderazgo, que cuentan con una oferta adecuada a distintos sectores socioeconómicos. Existe una literatura especializada al respecto que se vende en librerías y quioscos, y de forma ambulatoria en sus versiones piratas, así como una oferta en educación superior que apuesta por la formación de una generación de emprendedores. Este tipo de consumo de servicios y productos es central en la apropiación de repertorios culturales, que permiten a sujetos de distinta condición cultivarse, entrenarse y desempeñarse como emprendedores. De ese modo, la posibilidad de constituirse en emprendedor ciertamente ofrece a distintas personas y grupos sortear o resignificar las categorías clasificatorias de clase, etnicidad y raza, a las 
que han estado históricamente adscritos. Pero una mirada atenta y crítica a este proceso nos revela que la categoría de emprendedor no reemplaza ni elimina las categorías raciales, étnicas, de clase y de género, sino que esta más bien ha sido rápidamente incorporada en el sistema clasificatorio imperante. Por ejemplo, cuando el calificativo de emprendedor es racializado, o definido en términos de género y etnicidad, como sucede en la tipología por estilos de vida propuesta desde el marketing (Arellano, 2010).

La identificación de una nueva era marcada por el imaginario de la fusión, en los términos que Martuccelli lo plantea, exige introducir una discusión detallada de estas nuevas formas de clasificación y marginación social, porque es precisamente allí donde los mandatos propios de un régimen neoliberal se viven y disputan en el marco de una sociabilidad emergente. Si bien cuando Martuccelli se refiere al surgimiento de una nueva sociabilidad destaca el hecho de que esta no implica una transformación de las estructuras de poder, considero que su análisis queda corto debido a que sus referencias a la evidencia empírica acerca de los modos en que se ha reconfigurado la producción de las diferencias en Lima y el Perú se queda en lo meramente anecdótico. Una debilidad del libro es precisamente la falta de una exploración de campo sistemática dirigida a la creación de un archivo que permita identificar y discutir aquellos asuntos críticos para los distintos actores implicados en la ciudad de Lima.

Finalmente, quiero referirme al argumento de Martuccelli según el cual detrás de los procesos de constitución de un nuevo sujeto y una nueva sociabilidad habría un proyecto institucional. Pienso que esta afirmación se debe principalmente a la falta de una discusión sustentada en referentes empíricos. Por el contrario, el seguimiento de actores específicos y sus actuaciones y agendas permitiría discutir críticamente el argumento de un proyecto reglamentador sin sustento institucional. Una investigación de campo rápidamente nos remitiría a la existencia y actuación de aparatos institucionales —estatales y no estatales - que a través de los saberes emergentes, como la gestión y el marketing y sus expertos, operan como dispositivos de poder ejerciendo una fuerza normalizadora a través de la cual el emprendedurismo como ethos cultural, las lógicas corporativas como principios de acción legítimos y el emprendedor como actor social permean la totalidad de la vida social y definen los términos de lo posible. Es esta fuerza normalizadora la que define al propio Estado en su desempeño como una instancia de la gubernamentalidad neoliberal, instaurando formas de gobierno que se rigen por las lógicas corporativas, pero también la que desplaza el ejercicio del gobierno al ámbito corporativo. Afirmaría que más que una ausencia de institucionalidad 
gubernamental, habría un exceso de institucionalidad gubernamental, que se materializa en las distintas instancias de la cooperación público-privada. El argumento del proyecto reglamentador resulta, pues, problemático, en la medida en que se sustenta en una noción exclusivamente estatal de la gubernamentalidad,

\section{Gisela Cánepa Pontificia Universidad Católica del Perú}

\section{REFERENCIAS}

Arellando, Rolando (2010). Al medio hay sitio: crecimiento social según estilos de vida. Lima: Arellano Marketing, Planeta.

Cánepa, Gisela (2013). Nation Branding: The Re-foundation of Community, Citizenship and the State in the context of Neoliberalism in Perú. Medien Journal, 3, 7-18.

Cánepa, Gisela (2012). Gestión municipal como marca: identidad, espacio público y participación. Cuadernos. Arquitectura y ciudad, 16. Revista del Departamento Académico de Arquitectura, PUCP, 41-85.

Comaroff, Jean y John Comaroff (2009). Ethnicity INC. Chicago Studies in Practices of Meaning.

Cadena, Marisol de la (2004). Indígenas mestizos: raza y cultura en el Cusco. Lima: IEP.

Yúdice, George (2002). El recurso de la cultura: usos de la cultura en la era global. Barcelona: Gedisa.

Resumen

Discute las debilidades conceptuales del libro Lima y sus arenas de D. Martuccelli a través de una crítica a sus nociones de mestizaje, fusión, individuo híper actor y proyecto reglamentador. Palabras clave: régimen neoliberal, mestizaje, sujeto, fusión, gubernamentalidad. 